\title{
EDUCAÇÃO FÍSICA NO ENSINO SUPERIOR: UMA PRÁTICA \\ RESSIGNIFICADA COMO CONTEÚDO ACADÊMICO.
}

Rogério Rodrigues ${ }^{1}$

\begin{abstract}
Resumo
O problema analisado refere-se ao ensino da Educação Física instituída como disciplina obrigatória na grade curricular do Ensino Superior antes da promulgação da Lei $\mathrm{N}^{\circ}$ 9.394/96. Com a promulgação da referida lei, a obrigatoriedade deixou de existir e a Educação Física tornou-se uma disciplina destituída de significado acadêmica, praticamente extinta nos currículos dos diversos cursos de graduação. O objetivo é, portanto, estabelecer uma ressignifição da Educação Física no Ensino Superior como diretamente relacionada com a reformulação dos seus conteúdos. O método empregado é o da pesquisa participativa em virtude do pesquisador trabalhar com a disciplina Educação Física no Ensino Superior. A conclusão do trabalho aponta para a necessária inserção dos conteúdos da Educação Física nos três principais eixos norteadores do trabalho do docente no Ensino Superior, quais sejam, o ensino; a pesquisa e a extensão.
\end{abstract}

Palavra-Chave: Educação Física, Esporte, Ensino da Educação Física, Fundamentos da Educação Física.

${ }^{1}$ Doutor em educação pela Unicamp, Docente da UNIFEI.

\begin{abstract}
The problem analyzed relates the teaching of Physical Education instituted as a mandatory discipline in the curriculum of higher education before the promulgation of Law number 9.394/96. However, with the enactment of that law, the obligation no longer exists and Physical Education has become a devoid of meaning academic discipline, virtually extinct in the curricula of many undergraduate courses. The aim is therefore to establish a new meaning of physical education in higher education as something directly related to the reformulation of its contents. The method employed is that of participatory research because the researcher works with the Physical Education in Higher Education. The conclusion of the work points to the insertion of the required contents of physical education in the three main guiding principles of the teaching work in higher education such as teaching, research and extension.
\end{abstract}

Keywords: Physical Education, Sports, Teaching of Physical Education, Principles of Physical Education.

\section{INTRODUÇÃO}

\section{O ensino da Educação Física no Ensino Superior: uma atividade obrigatória antes da promulgação da Lei № 9.394/96 (LDB).}

Falar sobre o ensino da Educação Física no Ensino Superior ou sobre as denominadas práticas esportivas antes da promulgação da Lei $\mathrm{N}^{\circ}$ 9.394/96 (Lei Diretrizes e Base da Educação) é falar diretamente de sua 
obrigatoriedade como prática educativa e, portanto, analisar alguns elementos sobre a história da educação no Ensino Superior e observar que a inserção dessa atividade corporal na grade curricular se apresentava como a intencionalidade, basicamente, de estabelecer através das práticas esportivas o controle do tempo livre, a desarticulação do movimento político em reivindicar diversos aspectos democráticos, como, por exemplo, a ampliação de vagas no Ensino Superior e, principalmente, a promover a formação de um tipo de sujeito destituído de consciência crítica em relação aos diversos aspectos sociais. Isso se deve a um efeito muito peculiar do treinamento esportivo, ou seja, o controle do tempo livre está diretamente relacionado ao tempo ocupado pelo sujeito em seus treinamentos e, principalmente, aos períodos de recuperação. A desarticulação do movimento político ocorre pelo fato de que o sujeito se encontra ocupado com a sua preparação física, técnica e psicológica (GHIRALDELLI, 1988). A destituição da consciência crítica é um efeito direto do controle do tempo e da ocupação para os treinamentos. A Educação Física no Ensino Superior desempenhou uma função política ao estabelecer uma rotina de trabalho que a destituiu como conteúdo acadêmico e a instituiu como uma prática cega ${ }^{2}$, já que se encontrava, na universidade, alheia aos aspectos da formação intelectual do sujeito.

No conjunto dessas práticas esportivas oferecidas aos alunos dos diversos cursos de graduação, a Educação Física perdeu seu significado acadêmico e se constituiu como uma atividade física voltada para a promoção do talento esportivo, principalmente, através da organização de diversos tipos de campeonatos tendo como referência o esporte espetáculo ${ }^{3}$. No entanto, grande parte dos estudantes não podia assumir os compromissos de treinamento esportivo em razão dos seus estudos e, principalmente por não terem tempo disponível e nem a educação corporal que os habilitasse para o referido desempenho o que tornava as práticas esportivas na universidade algo paradoxal e sem sentido algum no meio acadêmico.

A implementação dos esportes como conteúdos da educação física, principalmente no Ensino Superior, apresenta-se de modo hegemônico, mais propriamente, a prática do jogo de futebol. O professor de educação física quando vai para a quadra deve quase que necessariamente deixar que seus 
alunos joguem futebol, pois trata-se de uma exigência a de que possam se divertir na aula. Afirma-se que, no campo da cultura corporal, vive-se um fechamento para uma única modalidade esportiva e isso promove a falta de compreensão do fenômeno esportivo. No campo da formação da cultura corporal no Ensino Superior instaura-se o "analfabetismo", pois pouco se compreende sobre as coisas do corpo.

Desta maneira as práticas esportivas na universidade são uma pequena imitação da vida esportiva dos clubes (de futebol) e se mantém a partir de alguns alunos que trazem em sua formação o treinamento corporal realizado nos clubes esportivos. O ensino da Educação Física se caracterizou aí como uma prática que, quando bem realizada, se constituia de treinamentos esportivos e na realização de campeonatos que tentavam minimamente imitar os modelos dos clubes esportivos.

Nessa situação das práticas esportivas no Ensino Superior, o docente da Educação Física pouco se aproximava de outros colegas pesquisadores do departamento e até mesmo o seu gabinete de trabalho era inexistente, pois seu efetivo trabalho era para ser realizado somente nas quadras "poli-esportivas" 4 , que na verdade deveriam se intitular quadras "mono-esportivas".

Com a ampliação dos diversos cursos de pós-graduação e com a redemocratização do país a partir dos anos 80, mais propriamente, com os movimentos populares, como o de "diretas já" (1984) que culminou com a “transição democrática", surge uma nova dimensão para o ensino da Educação Física na universidade. Os diversos cursos de formação dos profissionais da Educação Física reformularam suas grades curriculares de modo a criar um lugar para a reflexão onde se estabelecesse a pesquisa, o ensino e a extensão no sentido de proporcionar uma crítica direta à prática cega que sempre fez da Educação Física uma atividade sem sentido algum no campo escolar ${ }^{1}$.

\footnotetext{
${ }^{1}$ Sobre esse assunto podemos afirmar que a Educação Física no ensino superior se constituiu como uma continuidade das praticas esportivas sem significados da educação básica, ou seja, não posso deixar de lembrar que na condição de estudante do colegial (1979-1981) os meus professores de Educação Física ficaram os três anos com o seguinte modelo de aula de educação física: faziam a chamada; mandavam os alunos correr, geralmente, por doze minutos e depois eram dispensados. A avaliação
}

${ }^{4}$ Neste caso, lembro que nos primeiros dias de trabalho na antiga Escola Federal de Engenharia de Itajubá que tinha um colega de trabalho que passava em frente do meu gabinete e dizia: "eu não compreendo como um professor de educação física fica aqui na sala estudando". 
Partiu-se da suposição de que essa falta de transmissão da cultura corporal também se apresentou no ensino da Educação Física no nível superior, em que esta perdeu por completo o significado. O treinamento esportivo e os campeonatos não mais a justificavam na grade curricular e a disciplina Educação Física só se manteve no Ensino Superior por uma determinação da legislação educacional ${ }^{5}$. O problema tornou-se muito maior para a manutenção da Educação Física no Ensino Superior, pois a sua meta de esporte rendimento não estava se implementando no atendimento aos alunos que se encontravam dispostos a sacrificar-se para realizar os referidos treinamentos cuja exigência em relação à disciplina poucos conseguem suportar dadas as determinações em termos de práticas corporais. Essa falta de rigor nos treinamentos e a realização dos campeonatos fizeram do esporte universitário um lugar de baixo rendimento esportivo e de alto custo para sua manutenção.

Assim, com a promulgação da nova LDB (9.394/96), quando a Educação Física deixou de ser obrigatória no Ensino Superior, ocorreu uma inversão de todo o ufanismo na realização dos treinamentos e dos diversos campeonatos e isso acabou por direcioná-la para sua extinção na grade curricular dos diversos cursos de graduação e permanecendo apenas em algumas instituições de ensino com aspectos recreativos ou na manutenção de "turmas de treinamento"

Tendo como base esses acontecimentos referentes ao ensino da Educação Física no Ensino Superior este estudo buscará de um lado analisar as condições que levaram à perda de significado da Educação Física no Ensino Superior e de outro lado proporá o ensino da Educação Física no Ensino Superior de maneira que possa ser ressignificada com o estudo do movimento corporal que possa inserir a questão do ensino do uso técnico do corpo como um conteúdo passível de ser oferecido como uma disciplina e, principalmente,

(...) era a aplicação do "teste de Cooper" em que nos esforçávamos para alcançar a categoria "excelente", para tirar a nota máxima, ou seja, em doze minutos correr acima de 2800 metros. (COOPER, 1968). Em nenhum momento nesses três anos de colégio foi explicado o que era o "método de Cooper" e isso caracterizava a falta de compreensão sobre quais seriam os elementos da cultura corporal a serem transmitidos no campo escolar e, portanto, o ensino da educação física era apenas o cumprimento da legislação educacional, mais propriamente, a Lei n. 5.692/71 que instituiu em seu artigo $7^{\circ}$ a obrigatoriedade do ensino da Educação física como disciplina curricular. 
que possa justificar o ensino da Educação Física nos diversos cursos de graduação articulado com a pesquisa e a extensão. Deste modo, constroi-se a hipótese de que uma ruptura no modo de pensar a cultura corporal centrada na "prática alienante" proporcionará uma nova mentalidade a respeito da inserção da questão do corpo nos diversos cursos de graduação que se situem para além do reducionismo biológico.

\section{OBJETIVO}

\section{Da Educação Física que temos para a Educação Física que queremos: as} práticas esportivas destituídas de significados para a ressignificação das práticas corporais no campo da cultura.

Existem vários fatores que fazem da Educação Física uma prática destituída de significado no Ensino Superior. Supõe-se que isso evidencia um aspecto de ordem subjetiva diretamente relacionado com o modo como o uso do corpo é representado na sociedade de mercado. Dir-se-ia que o uso do corpo na sociedade de mercado, como qualquer outro produto que se deve apresentar como passível de consumo, pois há na sociedade um conjunto de práticas corporais que se representam como produto. Qualquer sujeito pode ingressar numa "academia de ginástica" e comprar a aula para aplicar em seu corpo uma determinada técnica ou podem-se vender as imagens de um evento esportivo para qualquer emissora de televisão. O que é mais difundido atualmente é o uso do corpo como um campo para a venda de diversos produtos, ou seja, através de mecanismos identificatórios fazer do corpo um lugar para o consumo de várias coisas.

No campo das "práticas esportivas" fica evidente que esse modo de compreender o uso do corpo como objeto/mercadoria também se encontra no interior da universidade e isso revelaria certas restrições por parte dos intelectuais. Certas formas de entendimentos fazem do uso do corpo uma mercadoria para o consumo e não apresentam referências acadêmicas. Uma "academia de ginástica" ou um "evento esportivo" apresentam, pois, dificuldade para serem analisados como objeto de pesquisa para fundamentar a criação de um laboratório de pesquisa no âmbito da universidade. Os seus 
acontecimentos interpretados como coisas corriqueiras da sociedade de mercado, infelizmente, não são assumidos com a devida importância em termos de relevância de estudo. Numa sociedade em que a televisão influencia como fator decisivo a formação de opinião pública, o exemplo mais apropriado das práticas corporais como algo destituído de significado são os diversos enredos das novelas que apresentam os personagens em torno dos cuidados do corpo como um conjunto de futilidades sem sentido algum para a vida e isso de certo modo afeta o imaginário de toda a população que inclusive se encontra no Ensino Superior.

Paradoxalmente, a essa situação de falta de representação para análise sobre o uso do corpo na universidade, os meios de comunicação realizam de maneira ostensiva diversas mesas de debates em que jogadores, técnicos, e outros profissionais discutem durante horas algum acontecimento esportivo. Tais debates extremamente prolongados não denotam uma reflexão crítica sobre o fenômeno esportivo e permanecem em expressões de sentimentos sem consistência nos argumentos. Veja-se, por exemplo, em referência a casos de violência das torcidas, os argumentos apresentados nesses debates é o de aumentar o valor dos ingressos para restringir o acesso das “torcidas organizadas". Quem se utiliza desse argumento é alguém que desconhece duas coisas: o mundo esportivo e os elementos desencadeadores da violência humana. Isto indica a premência de a universidade assumir o papel de orientar-se para a pesquisa e para a análise do uso do corpo como pertinente à pesquisa, ao ensino e à extensão. A Universidade além de assumir o papel no estudo do corpo como objeto interdisciplinar passível de ser estudado em diversos cursos de graduação deveria também implementar a divulgação do resultados dessas pesquisas a fim de favorecer a ampliação da cultura corporal na sociedade. O conjunto das chamadas "práticas esportivas" constituir-se-ia necessariamente como um elemento para ser analisado em interface com as diversas áreas do conhecimento.

Isso seria de fundamental importância para colaborar com a ruptura da situação não reflexiva sobre a questão do uso do corpo na sociedade de mercado. Neste posicionamento, qual seria o ponto central impeditivo da ruptura de uma Educação Física (práticas esportivas) destituída de significado para a construção de uma Educação Física crítica? Encontra-se em Pierre 
Bourdieu (1990) o apontamento sobre esse problema ao referir-se à dificuldade da sociologia do esporte ao afirmar que (...) grandes atletas negros, que nos Estados Unidos em geral são pagos por grandes universidades, como a Universidade de Stanford, vivem numa espécie de gueto dourado, pelo fato de as pessoas de direita não falarem de bom grado com os negros e as de esquerda não falarem de bom grado com os esportistas. Se refletirmos sobre isso, desenvolvendo-lhe o paradigma, talvez encontremos aqui o princípio das dificuldades particulares que a sociologia do esporte encontra: desdenhada pelos sociólogos, ela é desprezada pelos esportistas (BOURDIEU, 1990, p. 207).

Neste caso, obtêm-se outras derivações dessa reflexão de Bourdieu (1990) sobre a questão do uso do corpo e o impedimento para que se exercite na universidade o seu ensino de maneira crítica. De modo geral a Educação Física no Ensino Superior se constituiu como prática, mais propriamente, como prática esportiva em decorrência do Decreto-Lei que estabelece sua obrigatoriedade e isso fez dela um "gueto" como diz Bourdieu, portanto, devese exercitar a ruptura dessa situação induzindo os intelectuais de modo geral a se voltarem para a questão do uso do corpo como objeto de pesquisa ${ }^{6}$.

Para tanto, parte-se, basicamente, dos três eixos norteadores que justificam o trabalho docente na universidade, o ensino, a pesquisa e a extensão. Em relação ao ensino a Educação Física deve abandonar a condição de prática cega e apresentar-se com um elo indissociável com a ciência, mais propriamente, com a ciência do movimento corporal $^{7}$. Neste sentido, a questão do uso técnico do corpo pode ser tematizado em diversos cursos de graduação como um conteúdo que proporcionaria aos futuros intelectuais uma interpretação distinta sobre as coisas referente ao uso técnico do corpo. Em relação à pesquisa, esta é uma consequência direta da inovação sobre o ensino, ou seja, o docente responsável pela Educação Física deve estar apto a utilizarse da pesquisa como uma importante ferramenta no sentido de renovar o ensino da Educação Física.

O trabalho da extensão é peculiar com um mecanismo próprio para a divulgação da ciência e no caso da Educação Física seria preciso que esta 
pudesse romper com as práticas corporais destituidas de significado. No caso específico da extensão a demanda gira em torno de elementos a respeito dos quais a população, de modo geral, não busca esclarecimentos que possam estabelecer a crítica sobre a prática, a realização de uma modalidade prática que muitas vezes se aproxima do exercício da prática cega e aponta para um sério problema de metodologia de ensino, ou seja, como fazer de uma extensão da Educação Física uma prática esclarecedora e crítica sobre o movimento corporal?

Esse problema também se apresenta no ensino da Educação Física na graduação, ou seja, grande parte dos alunos não consegue encontrar um real motivo para fazer o estudo do movimento corporal, principalmente, em seus corpos. Isso faz do estudo da prática da Educação Física um elemento alheio à cultura erudita. Grande parte da demanda permanece em situações em que se busca na prática do movimento corporal apenas algo divertido, mais precisamente, a realização da alienação de si mesmo. Inverter essa situação é romper com as práticas corporais que estabelecem no corpo o culto da força ou do embelezamento como somente a realização da descarga pulsional do sujeito em relação ao objeto sem a possibilidade de representação. Compreende-se que essa perda da condição de elaborar os determinantes presentes no uso do corpo é o que mantém o sujeito alheio a si mesmo e preso em seu próprio narcisismo nas questões das coisas do corpo. A ruptura dessa situação seria encontrada na ciência por meio de conceitos que favoreçam os elementos críticos e isso faria da Educação Física um elemento importante para a interpretação da cultura corporal e que a justificasse como conteúdo presente no Ensino Superior inclusive como "práticas esportivas". 


\section{MÉTODOS}

\section{Pesquisando o movimento corporal: as relações entre a Educação Física e a transmissão dos conteúdos no âmbito da Universidade.}

Para pesquisar a Educação Física no Ensino Superior elegeu-se como proposição teórica a Filosofia da Educação para analisar e interpretar como se realiza essa junção entre o exercício das práticas corporais e a transmissão dos conteúdos. Em grande parte essa junção entre as práticas corporais e as diversas ciências não se realiza de maneira espontânea pelo simples motivo de que quem a pratica faz do seu corpo um objeto de aplicação e quem não a pratica pouco compreende como um pensamento se direciona para analisar as diversas coisas relacionadas ao uso do corpo (BOURDIEU, 1990). Neste contexto, a Universidade estabeleceria com o ensino da Educação Física um ponto para esse tipo de reflexão de cunho científico ou até mesmo filosófico e representativo para o estudo do movimento corporal e de outros elementos para a realização da "atividade física".

A falta de associação entre a prática e a teoria que se apresenta nas práticas corporais trabalhadas no ensino da Educação Física nos diversos cursos de graduação nas "práticas esportivas" a tornou uma prática cega. Os efeitos dessa atitude destituída de significado ao fazer as coisas com o corpo favoreceu o sujeito a alienar-se de si mesmo no campo da cultura.

Supõe-se que é possível partir das práticas corporais destituídas de significado, retomá-las e representá-las como elementos próprios da cultura corporal, passíveis de interpretação no campo das diversas ciências. Surge daí uma necessidade na insistência de que os cursos de formação dos pesquisadores seja na graduação através da iniciação científica ou na pós graduação (mestrado e doutorado) a condição de instrumentalizar para uma reflexão sobre o real educativo das coisas a respeito do uso do corpo de maneira ampliada. Esses elementos reflexivos sobre a educação corporal podem alterar a prática da Educação Física no Ensino Superior e, principalmente, na sociedade como um todo.

As características pertinentes da amostra dessa análise referem-se à escuta/olhar de prática de alguns professores de Educação Física com os quais 
o autor da pesquisa entrou em contato no momento em que também estava inserido como professor de Educação Física na unidade de ensino.

O método utilizado para a coleta foi o da pesquisa participativa. $\mathrm{Na}$ oportunidade, como professor da unidade de ensino tornou-se possível a compreensão da lógica que instituiu os diversos motivos que inviabilizam a realização da Educação Física como "práticas esportivas" com conteúdo acadêmico para os diversos cursos de graduação. A pesquisa de campo sobre a Educação Física no Ensino Superior é resultado de diversas anotações que permitem uma reflexão em que o próprio autor é responsável pela disciplina Educação Física nos cursos de graduação, portanto, a sustentabilidade dos argumentos está diretamente relacionada com o material acumulado durante quinze anos como professor da "prática" da Educação Física no Ensino Superior.

\section{RESULTADOS}

\section{A Educação Física no Ensino Superior: o movimento corporal como objeto de pesquisa, ensino e extensão.}

Como resultado dessa reflexão sobre o ensino da Educação Física no Ensino Superior considera-se que a manutenção da mesma na grade curricular vai depender diretamente de uma alteração no modo de analisar o uso corpo, uma superação de uma prática centrada somente no esporte que aliena o sujeito. A educação física como sinônimo de prática esportiva é paradoxal, pois apresenta vários tipos de demandas que a indicam como uma prática destituída de significado no âmbito da academia.

Para se iniciar o problema do ensino da educação física no Ensino Superior é importante destacar que há falta de compreensão do seu significado por grande parte daqueles que administram o referido sistema de ensino. De um lado, a educação física como prática de esporte não permite mantê-la na grade curricular dos cursos de graduação. De outro lado, os próprios alunos veem a prática do esporte como a única possibilidade de algum tipo de realização em ser sujeito numa sociedade que lhe tira quase todas as possibilidades de encontrar em si mesmo os processos de identificação. Desse modo, o ensino da educação física fica condenado ao desaparecimento no 
Ensino Superior por uma dupla via, pela extinção da obrigatoriedade e pelo modo como é compreendida pelos alunos como uma prática cega. $\mathrm{O}$ que resta para Educação Física no Ensino Superior são as práticas corporais assumidas como tarefas atléticas dos alunos, visto que eles assumem a função de organizar os campeonatos e os treinamentos.

Somente uma ruptura sobre o modo de pensar os cuidados com o corpo é tornará o ensino da Educação Física extremamente importante para a ampla formação do aluno. No entanto, ainda hoje é possível encontrar em diversos quadros administrativos a orientação de que a Educação Física no Ensino Superior deva ser trabalhada estritamente como uma prática esportiva tal como ocorre nos clubes. (GHIRALDELLI, 1988).

Há motivos diversos que justificam o esporte como prática educativa de um conteúdo específico no campo do ensino na universidade, mas a resposta sobre essa forma não crítica de ensinar os cuidados com o corpo é que muitos dos atuais administradores foram submetidos ao ensino da Educação Física obrigatória tendo o esporte como prática principal e sua reflexão limita-se, por esta razão, a esse universo da cultura corporal.

Uma nova proposição sobre o ensino da Educação Física requer uma abordagem científica para a realização das práticas corporais. Solicitar a um aluno que realize uma caminhada ou corrida por um determinado período de tempo é uma tarefa que deve propor algum tipo de compreensão que resulte em novas associações de pensamento. Um aluno do curso de Ciências Humanas interpretaria a caminhada ou a corrida como um processo de educação da subjetividade; o aluno do curso de Ciências Exatas analisaria as resultantes das forças que permitem o movimento corporal, e um aluno das Ciências Biológicas compreenderia o corpo humano como uma máquina que sintetiza diversas substâncias químicas para produzir a energia necessária para a realização da corrida. O ato da caminhada ou da corrida encontra-se ampliado e não se reduz ao ato propriamente realizado, embora o educador físico possa intervir na técnica que por sua vez alteraria a educação da subjetividade, as resultantes de força e o desempenho energético. Isto compõe 
o processo reflexivo daqueles que pensam o corpo como um objeto de estudo e de pesquisa.

\section{DISCUSSÃO}

\section{Em busca de novos modelos para o ensino da Educação Física no Ensino Superior.}

Durante muitos anos como docente da disciplina Educação Física no Ensino Superior venho fazendo duas coisas, primeiramente, apresentando a Educação Física como uma prática passível de ser conceituada e em segundo afirmando aos meus alunos que é preciso pensar as questões do uso do corpo como um lugar de trabalho e pesquisa e não somente para a realização de uma prática cega.

Esse modo de trabalhar a prática de Educação Física torna-se um convite para que diversos intelectuais pensem as questões do corpo. Manter a prática da Educação Física nos vários cursos de graduação passa ser um elemento estratégico para que as diversas áreas do conhecimento se voltem para esse objeto de estudo. Nota-se, contudo, que grande parte dos alunos do curso de Educação Física no Ensino Superior parecem não querer pensar as questões do corpo e demonstram buscar apenas uma prática que os satisfaça, principalmente, no futebol, que, embora seja um esporte, nestas circunstâncias se resume a chutar e a gritar. A prática corporal estratificou-se, de modo hegemônico, como uma descarga pulsional e torna impossível qualquer reflexão sobre as questões do movimento corporal. Neste contexto, a própria existência do professor de Educação Física perde o sentido, visto que os alunos querem somente uma bola para ficar "se divertindo".

Quando se propõe para esses alunos alguma reflexão sobre as questões do corpo é muito casual a recusa, pois eles foram educados nas aulas de Educação Física para somente fazer e não para pensar as coisas com o corpo. Isso é tão verdadeiro que quando se usa o corpo, muitas vezes não se sabe como as coisas ocorrem e é de modo inconsciente que se realiza a maneira de utilização do corpo.

O corpo expressa uma lógica que muitas vezes não passa pelas palavras. A falta de comprensão desse elemento não verbal sobre as coisas do 
corpo por parte do profissional da Educação Física tem produzido a referida educação do corpo destituída de significado. Isso se deve em grande parte ao fato de que as teorias educativas não tornam possível compreender a prática da educação do corpo. Cabe aos novos modelos para o ensino da Educação Física apropriarem-se dessa forma silenciosa de educar o corpo como objeto de pesquisa para que o seu ensino se constituia pelo viés da crítica e, portanto, justifique sua presença nos diversos cursos de graduação no Ensino Superior.

\section{CONCLUSÃO}

\section{Para uma Educação Física no Ensino Superior}

Analisar a Educação Física no ensino superior e, principalmente, a transmissão da educação do corpo é tão peculiar que faz dessa prática educativa algo que se encontra para além do "exercício físico", ou seja, o ponto central no ensino da Educação Física deveria ser o aprimoramento do "pensamento científico".

Nesta "metodologia do ensino" a Educação Física e pensamento estão circunscritos por um simbolismo em que a ciência apresenta-se como uma forma de interpretação das práticas corporais. Essa premissa de ensino da Educação Física permite um longo diálogo entre todos os praticantes, portanto, uma intensa reflexão sobre a prática, qual seja, de como é possível fazer as coisas com o corpo que por mais simples que seja possui um significado ampliado no campo das ciências. Em parte esta contribuição destituiria os guetos de determinadas práticas corporais que se encontram isoladas e, no caso específico da "Pedagogia do Movimento Humano" um amplo campo de pesquisa que traria a possibilidade de ampliar a compreensão de diversas modalidades de educação do corpo como conteúdo acadêmico no ensino superior. 


\section{REFERÊNCIAS}

BOURDIEU, P. Coisas ditas. Trad. Cássia R. da Silveira e Denise Moreno Pegorim. São Paulo: Brasiliense, 1990.

COOPER, K. Aptidão Física em qualquer idade. Rio de Janeiro: Forum, 1968.

GHILRALDELli Jr, P. Educação Física Progressista. São Paulo: Edições Loyola, 1998.

MOREIRA, W. W. Educação física escolar: uma abordagem fenomenológica. 2. ed. Campinas: Editora da Unicamp, 1992. SHUMWAY-COOK, A.; WOOLLACOTT, M. H. Controle motor: teoria e aplicações práticas. 2. ed. São Paulo: Manole, 2003. 